University of New Mexico

UNM Digital Repository

Shared Knowledge Conference

Nov 8th, 11:00 AM - 1:00 PM

\title{
Estimating Tea Plantation Area Based on Multi-source Satellite Data
}

Yanhong Huang

University of New Mexico

Follow this and additional works at: https://digitalrepository.unm.edu/skc

Huang, Yanhong. "Estimating Tea Plantation Area Based on Multi-source Satellite Data." (2021). https://digitalrepository.unm.edu/skc/2021/Posters/38

This Event is brought to you for free and open access by UNM Digital Repository. It has been accepted for inclusion in Shared Knowledge Conference by an authorized administrator of UNM Digital Repository. For more information, please contact disc@unm.edu. 


\title{
Estimating Tea Plantation Area Based on Multi-source Satellite Data
}

Yanhong Huang, Department of Geography \& Environmental Studies, University of New Mexico, New Mexico State, Unted States, huangyh0906@unm.edu

Xi Gong, Department of Geography \& Environmental Studies, University of New Mexico, New Mexico State, United States xigong@unm.edu

Jingfeng Huang, Institute of Remote Sensing and Information Application, Zhejiang University, Hangzhou City, China, hjf@zju.edu.cn

\begin{abstract}
Tea is a characteristic cash crop native to China, mainly distributed in the south of the Yangtze River. Estimating the planting area and spatial distribution of tea gardens is of great significance to improve the economic and ecological benefits of tea. In this paper, a method for extracting tea plantation area based on multi-source remote sensing satellite data was proposed. We collected the Landsat 8 OLI, Sentinel-2, HJ-1A/B, and GF-1 WFV data from 2017 to 2018 in Huzhou City, China. After data pre-processing, we calculated the Normalized Difference Vegetation Index (NDVI) and spectral characteristics of each dataset. We also obtained Gabor textual features of each dataset using principal component analysis (PCA). In order to obtain the time-series data, all features of Sentinel-2, HJ-1A/B, and GF-1 WFV data were relatively calibrated to Landsat 8 OLI data Finally, the area of tea garden of Huzhou City, Zhejiang Province was extracted from each dataset using support vector machine (SVM) classifier. The area is $235.68 \mathrm{~km}^{2}$ and has been verified by data from field survey and Google Earth. The results show that this method can achieve high estimating precision for tea garden area estimation, which is of great significance for further application.
\end{abstract}

